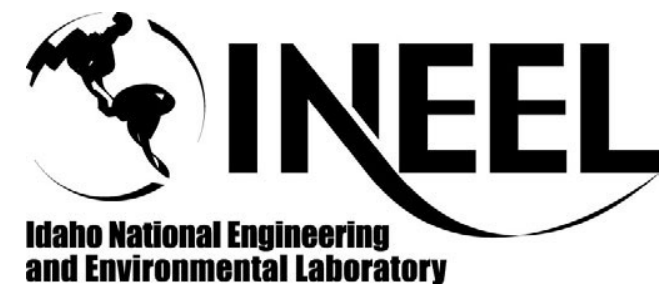

\author{
INEEL/CON-04-01685 \\ PREPRINT
}

Using Information From Operating Experience
To Inform Human Reliability Analysis

Bruce P. Hallbert

David I. Gertman

Julie Marble

Erasmia Lois

Nathan Siu

June 14-18, 2004

International Conference On Probabilistic Safety Assessment And Management

This is a preprint of a paper intended for publication in a journal or proceedings. Since changes may be made before publication, this preprint should not be cited or reproduced without permission of the author.

This document was prepared as an account of work sponsored by an agency of the United States Government. Neither the United States Government nor any agency thereof, or any of their employees, makes any warranty, expressed or implied, or assumes any legal liability or responsibility for any third party's use, or the results of such use, of any information, apparatus, product or process disclosed in this report, or represents that its use by such third party would not infringe privately owned rights. The views expressed in this paper are not necessarily those of the U.S. Government or the sponsoring agency. 


\title{
Using Information from Operating Experience to Inform Human Reliability Analysis
}

\author{
Bruce P. Hallbert, David I. Gertman, Julie Marble \\ Idaho National Engineering and Environmental Laboratory \\ Idaho Falls ID 83415 USA \\ Erasmia Lois, Nathan Siu \\ U.S. Nuclear Regulatory Commision \\ Washington, D.C. USA 20015
}

\begin{abstract}
This paper reports on efforts being sponsored by the U.S. NRC and performed by INEEL to develop a technical basis and perform work to extract information from sources for use in HRA. This work currently emphasizes extracting information from operational events. An anticipated benefit from this research is that it may provide the methodological tools needed to make greater use of more types of information in future HRAs and reduce uncertainties in the information used to conduct human reliability assessments.
\end{abstract}

\section{Uncertainty in Human Reliability Analysis}

The basic event probabilities in probabilistic risk assessment (PRA) associated with failed human actions are often the product of a specific human reliability analysis (HRA) method. HRA methods provide a systematic process for estimating the likelihood of human failures for different human actions. Most HRA methods either allow or direct the analyst to account for the impact of prevailing conditions on the performance of personnel modeled in the analysis. These conditions are variously named by HRA methods. In some cases, this may reflect important theoretical distinctions underlying the explanation and prediction of human performance espoused by a particular method; in other cases this may simply reflect minor distinctions in terminology. For example, Swain and Guttman [1] noted these influences as performance shaping factors - a concept several HRA methods have adopted. Recently developed methods have expanded upon this concept and emphasize greater use of information about context and performance conditions in 
analyses[2,3].

A challenge for human reliability continues to be identifying important contextual factors for inclusion in human reliability analyses and accounting for their influence. There are differences in the specific factors employed by different HRA methods for adjusting the nominal values of error rates. Considerable analyst judgment is required to identify factors that may affect the reliability of a candidate human activity and to estimate their effects on the conditional expectation of success or failure. Variability in the estimated magnitude of effect of these factors contributes to the uncertainty of the resultant risk metric and may contribute to systematic bias in the perceived importance of these factors on performance reliability. As a consequence of differences in analyst approaches to employing and assessing such factors, estimated failures may have a tendency to become conservative or optimistic in their treatment of human performance. This reflects systematic trends in analyst judgment using HRA methods when accounting for the effects of the elements of context that affect human performance.

The following illustrates how uncertainty regarding contextual factors may affect distributions of human performance reliability estimates. Figure 1 summarizes the conditional human error probabilities estimated using the SPAR-H HRA method[4]. This distribution was obtained by assuming that the ratings of most PSFs would follow a normal distribution and simulating 1,000,000 observations using Monte Carlo simulation. The nominal or expected value of the PSF occurred in most calculations; other values of the PSFs, either more or less favorable, occurred less frequently following an expectation function following that of a normally distributed random variable. The resultant distribution reflecting the product of a set of normally distributed random variables will tend toward a lognormal distribution. That is:

The distribution of X (the distribution of the SPAR-H HEP estimates) will have the characteristic lognormal distribution parameters:

and

, the first two moments of the lognormal distribution.

The cumulative percentage in Figure 1 shows that approximately $20 \%$ of the distribution lies below $0.01 ; 60 \%$ between 0.01 and 0.1 ; and $20 \%$ of the distribution lies above 0.1 in the range. The base HEPs for the SPAR-H elements of diagnosis and action are 0.001 and 0.01 respectively. The distribution shows the influence of the PSFs on the nominal HEPs without any systematic bias in the underlying 
judgments. Furthermore, this distribution might be considered conservative with respect to its expected values, owing in large part to the influence and uncertainty assumed in the PSF ratings. We can observe that improvements in knowledge about PSFs would serve to reduce the uncertainty in the distribution and may serve to attenuate some of the peak values in favor of a more lognormally distributed variable. This phenomenon affects many HRA methods currently employed; the SPAR-H method is as sensitive to such uncertainties as are other methods. It was chosen to illustrate these effects because it is similar to many HRA approaches in its treatment of shaping factors in quantification.

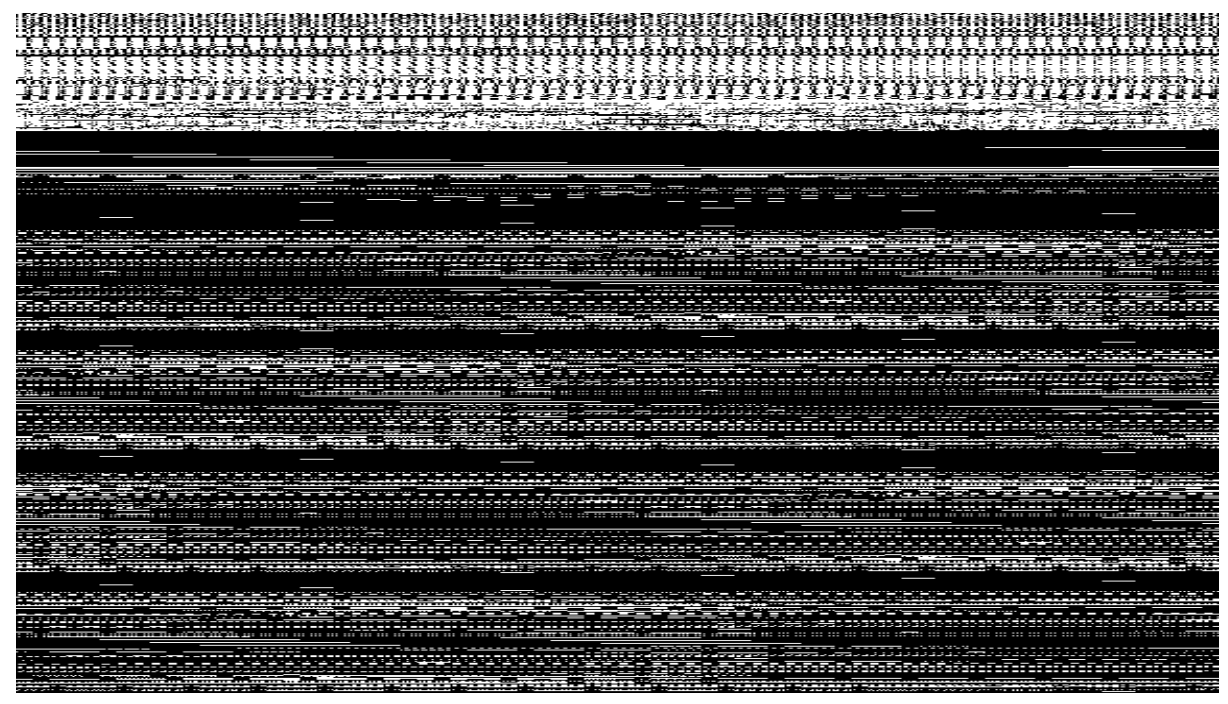

\section{Approach}

The objectives of this work are to: 1) develop a method for conducting risk-informed event analysis of human performance information that stems from operating experience at nuclear power plants and for compiling and documenting the results in a structured manner; 2) provide information from these analyses for use in risk-informed and performance-based regulatory activities; 3 ) create methods for information extraction and a repository for this information that, likewise, support a variety of HRA methods.

We reviewed a number of contemporary HRA methods including ASEP, ATHEANA, 
CODA, CAHR, CREAM, HEART, MERMOS, and SPAR-H. The reviews were performed to identify the kinds of information that analysts may need to apply these methods. Related international efforts [5] were also reviewed to assist in identifying a set of recommended information categories and a structure for reporting information and to allow for the eventual incorporation of a broader set of information sources. The internal structure of the resulting repository, termed HERA, is intended to meet the requirements of most common first- and second-generation HRA methods. The internal structure of HERA may not reflect the needs of any single HRA method; its information support a variety of methods that may be obtained through structured search or through the development of user-oriented interfaces that are tailored to suit a specific method or application.

\section{Results}

HERA has nine indices for information: Profile; Event time line; Diagnosis and Planning; Action; Plant complexity factors; Latent and maintenance complexity factors; Dependency; Human Action or success table; and Error type. These are described below.

The profile contains the plant name, plant type, event type, human action context, plant operating mode, failure type, and event summary. The profile also links to a graphic representation of the event time line. The profile provides a summary or synopsis of the operating experience including the specific human and system related actions and resulting context in which performance occurred.

The Event time line provides a text summary of the sequential human failure and success sub-events that occurred in the event. The event time line provides a time-based event progression that includes latent or pre-initiator conditions, initiating events, and post-initiator actions and activities. The graphic time line contains the sub events most critical to the progression and termination of the event. It distinguishes between unsafe acts and human actions where such information can be derived from event reports.

Diagnosis, Planning or Action sources contain information about performance shaping factors that were deemed present in the operating event. Human actions are classified according to whether they were primarily cognitive or behavioral in nature - based in diagnosis, planning or the execution of an activity. Seven performance shaping factors have been used to characterize contextual factors' influence on performance. These include: time available; stress; complexity; experience and 
training; procedures; fitness for duty; and work processes. The diagnosis and planning source is considered as a separate source from Action as they are typically exclusive. That is, a human action is coded as one or the other unless it is sufficiently ambiguous and the specific human error cannot be ascertained.

Plant Complexity Factors include information regarding the manifestation of the failures in plant systems and the demands placed upon plant personnel by the initiating and other related events. Plant complexity factors were derived primarily through research by the OECD Halden Reactor Project on factors influencing control room operator performance. They are used in HERA as an index of plant conditions.

Latent and Maintenance complexity factors provide information about plant and other conditions that affect the performance of non-operations work groups in the plant. This includes some factors that are similar to those associated with operations such as written procedures, training and qualifications, and human machine interfaces. It also includes some factors that are key to effective performance of maintenance, test, and surveillance activities such as work planning and preparation, skill of crafts, design configuration, equipment specification, and construction.

Dependency is used to describe when information points to relationships between sub events in the analysis. Failures or successes of individual activities may create a greater likelihood for failure or success of succeeding actions. Where it is possible to infer such relationships, HERA contains descriptions of the nature of the dependency between sub events.

Every event described in LERs and other sources has been terminated successfully through human intervention in many cases. The human actions success table documents the actions that were taken by plant personnel to mitigate the progression of the event. Successful human actions are an important feature of events and may be overlooked in studies of human failure. Together with human failure events, successful human actions provide a complete description of human performance in operating events.

Error type information in HERA provides a rough classification of the nature of the human failure sub event. The classification follows a taxonomy of slip, lapse, mistake, or violation.

During 2003, fourteen events were analyzed following a process that employs multi-disciplinary review of operating events to derive the information described above. Events were selected during the first year's effort that involve failure, detection, and restoration of emergency diesel generator systems. The aim of the 
reviews was to begin with analyses involving failure of similar, risk-relevant plant systems, and to consider development of methods for using this information to inform activities that could employ such information. The use of Bayesian techniques, for example, is under consideration to make use of information in HERA. Seventy-four individual human failure and success sub events were identified and analyzed by this process and entered into HERA.

\section{Future Direction}

Following the completion of these initial information extraction activities, a workshop was held to review the results of activities. Workshop attendees included NRC staff and contractor personnel involved or familiar with this project including potential users of HERA. Workshop attendees identified a number of near term and longer term goals for the system, including enhancements to data quality and quantity, tailoring and restructuring of information categories, user capabilities for searching and analysis using HERA, and aligning development with ongoing NRC projects and activities to enhance system use and development.

The focus of the current work has been on creation and usability of the back-end or data entry portion of HERA although the eventual goal is to enable user-initiated search and summary functions to support regulatory applications. Efforts to guide extraction and data entry are necessary and affect the kinds and quality of future user-system interaction. The aim of extracting information from operating experience has been to enable use of this information in future human reliability analyses. These information extraction activities have emphasized providing information on a range of information categories broadly useful to the most common first- and second-generation HRA methods. The eventual goal of these efforts is to improve the means by which the range of effects that performance shaping factors and other elements of context are accounted for in reliability analyses. Together with new methods and enhancements to existing methods, such information may be used to reduce the uncertainty in human reliability analyses, and improve our ability to make predictions of risk.

\section{References}

1. Swain, A.D., \& Guttman, H. The Technique for Human Error Rate Prediction. NUREG/CR-1278. U.S. Nuclear Regulatory Commission, Washington, D.C. 1984.

2. Cooper, S., Ramey-Smith, A., Wreathall, J., Parry, G., Bley, D., Luckas, W., Taylor, J., \& Barriere, M. A technique for human error analysis (ATHEANA) - 
Technical basis and methodology description. NUREG/CR-6350.

Washington D.C. U.S. Nuclear Regulatory Commission, 1996.

3. Hollnagel, E. Cognitive Reliability and Error Analysis Method (CREAM). Ameterdam, Elsevier, 1998.

4. Gertman, D.I., Blackman, H.S., Byers, J. et al. SPAR-H Method. DRAFT NUREG/CR in preparation, INEEL/EXT-02-10307.

5. Internatinal Atomic Energy Agency. Guidelines for describing human factors in the IRS (Human actions and related causal factors aznd root causes). Report of a consultants meeting organized by the International Atomic Energy Agency, IAEA-J4-CS-10/xx, Vienna, Austria, 19-23 March 2001.

\section{Disclaimer}

This report was prepared as an account of work sponsored by an agency of the United Sates Government. Neither the United States Government nor any agency thereof, or any of their employees, makes any warranty, expressed or implied, or assumes any legal liability or responsibility for any third party's use, or the results of such use, of any information, apparatus, product or process disclosed in this report, or represents that its use by such third party would not infringe privately owned rights. 